\title{
El precio de los productos y la venta de carne en los tratados de hisba andalusíes
}

\author{
The Price of Products and the Sale of Meat in the \\ Hisba Andalusi Treatises
}

\author{
María Crego \\ Universidad Pablo de Olavide de Sevilla \\ https://orcid.org/0000-0002-3042-7430
}

\begin{abstract}
El tema de los precios y su fijación es uno de los aspectos recogidos en los tratados árabes de hisba que más interés está suscitando en los últimos años entre estudiosos de diversos ámbitos, como los especialistas en contabilidad. Teniendo en cuenta la atención que los últimos estudios en historia económica prestan a ciertas herramientas contables, como el cálculo de costes, el presente trabajo analiza cómo los distintos tratados de hisba andalusíes tratan el tema de los precios de los productos y, en particular, las condiciones de venta de la carne y su precio. El análisis de los textos árabes revela un sistema tarifario complejo que se presta a la controversia - pues conviven la doctrina islámica con la costumbre y la posible comisión de fraudes- $\mathrm{y}$, al mismo tiempo, el deseo de la autoridad de intervenir en la regulación del zoco para la consecución de un precio considerado justo.
\end{abstract}

Palabras clave: hisba, al-Andalus, contabilidad.
Prices and their fixation, one of the economic subjects for medieval hisba treatises, is one of the issues that is arousing interest in the latest years among Accounting Historians. Given that recent studies in Economic History pay attention to certain accounting tools, such as costs accounting, this work focuses on the prices of commodities and, specially, the conditions of sale of the meat and its price, according to the data provided by the hisba Andalusi treatises. The study of these Arabic texts shows a complex and controversial price system, which reflects Islamic law and customs, but also the existence of fraud. It was certainly the intention of the judicial authorities to take part in market control of the fair sale prices.

Key words: hisba, al-Andalus, accounting.

Uno de los muchos temas de los que se ocupan los tratados de hisba ${ }^{1}$ medievales es el establecimiento de los precios de los productos.

${ }^{1}$ Sobre esta institución, véase $E I^{2}$, III, pp. 503-510; Chalmeta, El 'señor del zoco'en España y El zoco medieval. Contribución al estudio de la historia del mercado.

Copyright: (C) 2018 CSIC. Este es un artículo de acceso abierto distribuido bajo los términos de la licencia de uso y distribución Creative Commons Reconocimiento 4.0 Internacional (CC BY 4.0). 
Junto a los numerosos datos sociológicos y económicos que este tipo de obras nos ofrece - y entre los más importantes hemos de destacar la comprobación de medidas y pesas, el control de los fraudes y la vigilancia del comportamiento de las gentes del zoco-, éste de los precios es uno de los aspectos que en los últimos tiempos está suscitando un renovado interés por parte de distintos especialistas, y no sólo filólogos o historiadores.

De hecho, en los últimos años se han publicado trabajos que analizan los manuales de hisba desde el punto de vista de la contabilidad ${ }^{2}$, revelando procedimientos como el cálculo de costes, presente ya en el Kitā $b$ fi a a dāb al-his $b a^{3}$. Dicho tratado, redactado en época almohade, entre 1147 y 1236, está atribuido a Abū 'Abd Allāh Muhammad b. Abī Muhammad al-Saqați ${ }^{4}$ (m. después de 512/1118), quien desempeñó el cargo de almotacén en el zoco de Málaga. Escrita probablemente por uno de sus discípulos a partir de sus enseñanzas, la obra parte de la propia experiencia de al-Saqațī, reflejada en la variadísima casuística incorporada a la misma. Estamos ante un libro de consulta para el almotacén, orientado sobre todo a la supervisión de los oficios y la prevención de los fraudes de vendedores o fabricantes. Se trata de una obra muy extensa, de carácter normativo y mucho más técnica que el resto de los tratados de hisba andalusíes.

La presente contribución pretende, desde un punto de vista filológico, por un lado, ofrecer un panorama del tema de la fijación de los precios de acuerdo con los distintos tratados de hisba andalusíes y, por otro, a partir del análisis de los textos originales árabes no considerados en el trabajo de J. D. López et al. citado antes, ampliar éste último por lo que se refiere a la venta de carne y al establecimiento de su precio. Se tendrán en cuenta los tratados cronológicamente anteriores al de alSaqați que incorporan normativas relativas a la carne, tampoco reco-

\footnotetext{
${ }^{2}$ Para conocer el estado de la cuestión en torno a la contabilidad islámica y un análisis del propio concepto de "contabilidad islámica" y sus motivaciones religiosas, consúltese Napier, "Defining Islamic accounting".

${ }^{3}$ Véase López Manjón, Gutiérrez Hidalgo y Carrasco Fenech, "El olvido de un sistema de cálculo de costes andalusí", donde se estudia el cálculo de costes para la carne y el pan incluido en el Kitāb fì ādāb al-hisba.

${ }^{4}$ Ed. Colin y Lévi-Provençal, Un manuel hispanique de hisba. La traducción al español, de P. Chalmeta, se publicó en "El Kitâb fì ādāb al-ḥisba (Libro del buen gobierno del zoco) de Al-Saqațī". Sobre al-Saqațī, consúltese la introducción de Chalmeta a la traducción, así como, del mismo autor, "Al-Saqațī, Abū 'Abd Allāh".
} 
gidas de manera sistemática en el artículo mencionado y que, sin embargo, constituyen en algún caso (Ibn ${ }^{~}$ Umar) un antecedente del modo en que han de fijarse los precios con respecto a la carne. La intención del trabajo no es describir un sistema general de precios en al-Andalus, concepto discutible y que, en todo caso, requeriría un estudio monográfico.

Finalmente, señalaremos cómo la formulación teórica del cálculo de costes, procedimiento técnicamente complejo que se utiliza en la fijación de los precios, ya aparece en la Muqaddima de Ibn Jaldūn, lo que constituye un ejemplo más de que los sistemas de contabilidad avanzados no surgen en época contemporánea, sino que tienen sus precedentes en el período medieval.

Además de la obra de al-Saqațī, nos serviremos como base documental de los manuales de hisba de Yahyà b. ${ }^{~} \operatorname{Umar}^{5}$ (m. 289/901), Aḥmad b. 'Abd Allāh b. 'Abd al-Ra'ūf ${ }^{6}$ (s. X), Ibn 'Abdūn7 (ss. XI-XII) y, por último, 'Umar al-Ŷarsīifi (s. XIII), autor magrebí que algunos especialistas, siguiendo a Lévi-Provençal, incorporan al catálogo de obras de hisba andalusíes por el hecho de que residió en al-Andalus9.

La naturaleza de estas obras es heterogénea y, si bien todas pueden enmarcarse dentro del género de la hisba, debemos puntualizar que responden a distintas tipologías textuales ${ }^{10}$. En el caso de las dos primeras

${ }^{5}$ El Kitāb ahkām al-sūq fue editado en 1956 por Makkī, "Nașs ŷadīd fì l-hisba: Kitāb aḥkām al-sūq li Yahyyà b. 'Umar al-Andalusî”, pp. 59-151, traducido por García Gómez en "Unas ordenanzas del zoco del s. IX", pp. 253-316. Para el texto árabe, sigo la edición más reciente del propio Makkī: Yahyà Ibn 'Umar, Kitāb aḥkām al-sūq.

${ }^{6}$ Ed. en Ibn 'Abd al-Ra'ūf, Risāla fì ādāb al-hisba en Trois traités hispaniques de hisba, pp. 67-116 y trad. en Arié, "Traduction annotée et commentée des traités de hisba", I/1, pp. 5-38, I/2, pp. 199-214, I/3, pp. 349-386.

${ }^{7}$ Risāla fì l-qădā' wa-l-hisba (ed. Lévi-Provençal) "Un document sur la vie urbaine et les corps de métiers à Séville”, pp. 177-299 y la posterior en Trois traités hispaniques, pp. 3-65, traducido por García Gómez, Sevilla a comienzos del s. XII.

${ }^{8}$ Ed. Lévi-Provençal, Trois traités hispaniques, pp. 117-128 y trad. Arié, "Traduction annotée", pp. 365-375.

${ }^{9}$ Véase la n. 1 de una traducción anterior al inglés, Wickens, "Al-Jarsīfĩ on the hisba".

${ }^{10}$ Sobre el debate acerca de si la actuación de los zabazoques estaba o no basada, antes de época almorávide, en la costumbre y en la tradición oral -y a través de las obras de hisba se buscaría una "aprobación moral" a su trabajo dentro de la ley islámica-, véase Chalmeta, El zoco medieval, pp. 473-475. García Gómez, en la introducción a su traducción del tratado de Ibn 'Umar, "Unas ordenanzas del zoco del s. IX", p. 263, afirmaba lo siguiente: "que la hisba se basa y sustenta en el fiqh es axiomático y no necesita demostración ni discusión". 
obras citadas, el Kitāb ahkām al-sūq y la Risāla fì ādāb al-hisba, son tratados donde se trasluce la necesidad que tiene el almotacén de recibir por parte del derecho islámico una cobertura legal a sus actuaciones. No en vano, el tratado de Ibn 'Umar resulta ser una recopilación de consultas jurídicas formuladas por los zabazoques. Y, por su parte, la Risāla fì âdāb al-hisba no trata exclusivamente temas relativos al mercado, sino otros muchos vinculados a la práctica religiosa, como la oración, el ayuno, los matrimonios o los funerales, por lo que de nuevo se observa una preocupación por enmarcar la hisba dentro de los principios o exigencias de la ley islámica.

Las obras de Ibn 'Abdūn y al-Saqațī son mucho más ricas en detalles y responden a un modelo formal donde la hisba aparece ya como una disciplina estructurada. Al zabazoque se le exige ahora ser alfaquí, ser conocedor de la ley islámica, y aunque su jurisdicción es muy amplia, sus funciones principales serán comprobar las pesas y medidas e intervenir en el establecimiento de los precios. El tratado de al-Saqațī, en particular, es el más extenso de todos y el más técnico, como ya se ha dicho, y persigue un fin esencialmente práctico. Y es en esta obra donde se observa la necesidad de recoger una regulación muy pormenorizada que pueda servir para resolver los casos particulares de la vida diaria del mercado.

\section{La fijación de los precios en los tratados de hisba andalusíes}

Tanto la tarificación de los productos como la preocupación por el precio de las cosas están muy presentes en las obras de hisba ${ }^{11}$, dado que una de las funciones atribuidas al almotacén era la fijación de los precios y su control ${ }^{12}$. El Kitāb aḥkām al-sūq de Ibn 'Umar, el tratado

\footnotetext{
${ }^{11}$ Sobre la consideración teórica de los precios desde la perspectiva de la teología musulmana y las posibles formas de intervención en los mismos según los juristas de las distintas escuelas, consúltese Gimaret, "Les theologiens musulmans devant la hausse des prix" y Talbi, "Fiqh et taxation (tas 'îr)". En este último trabajo se afirma que las obras de hisba nunca mencionan explícitamente la fijación de precios entre las atribuciones del almotacén (véase p. 153), pero a continuación veremos que en el caso de los tratados andalusíes, no utilizados en dicho artículo -salvo la obra de Yahyà b. 'Umar-, sí se contempla esta tarea dentro de sus competencias.

${ }^{12}$ Junto a otras muchas atribuciones relativas a la moral y a la aplicación de la ley, por lo que su función estaría en ocasiones cercana a la de otros cargos de la administración is- 
andalusí más antiguo relativo a la hisba, refleja ya el interés por los precios, su regulación y el conocimiento que de ellos tienen las gentes. En esta obra se recogen dos opiniones distintas sobre si los precios del zoco de Qayrawān ${ }^{13}$ debían o no ser de aplicación en los zocos de la comarca ${ }^{14}$, poniendo así de manifiesto la existencia de dos modelos comerciales, urbano y rural, relacionados entre sí pero que mantenían sistemas de regulación diferentes. La obra de Ibn 'Abd al-Ra'ūf, de la escuela mālikí, también incluye algunas consideraciones sobre los precios de carácter general. Su autor, que al parecer desempeñó el cargo de zalmedina ${ }^{15}$ en Córdoba, a cuyo mercado bien podría referirse el tratado, alude, por ejemplo, a la prohibición destinada a los comerciantes de telas de revertir el salario de los intermediarios en el precio, pues no es lícito que el comprador sufrague ese salario ${ }^{16}$. El tratado de Ibn 'Abdūn, a pesar de no ser una obra muy técnica y no hacer apenas referencia a la fijación de los precios, sí recoge algunas alusiones a los mismos, como la necesidad de que las distintas clases de los alimentos tengan también precios diferentes, como en el caso de los higos buenos $\mathrm{y}$ malos y los pequeños y grandes ${ }^{17}$.

Otro de los temas presentes en este tipo de obras es el del acaparamiento. Ibn 'Abd al-Ra'ūf establece su prohibición, norma que, en caso de ser infringida, supone la confiscación de la mercancía y su distribución entre las gentes y los necesitados. Para ello, se tendrá en cuenta el

lámica como el șạhhib al-šurța, en ocasiones simultaneado con el de almotacén, o el qāậ̀. Müller, en su Gerichtspraxis im Stadtstaat Córdoba, p. 309, señala con respecto al período de Taifas que "Die untersuchten Prozesse des Cordobeser Marktvogts lassen vielfältige Überschneidungen mit anderen Gerichtsbarkeiten, insbesondere mit denen des $q \bar{a} a \underline{d} \bar{l} l$ ğamā'a, erkennen"; acerca de la participación de los almotacenes en los procesos judiciales en la Córdoba del s. XI, véanse, en esta misma obra, pp. 283-399.

${ }^{13} \mathrm{Su}$ autor, andalusí de Jaén, se instaló en esta ciudad magrebí.

${ }^{14}$ Yaḥyà Ibn 'Umar, Kitāb aḥkām al-sūq, p. 52; García Gómez, "Unas ordenanzas del zoco del s. IX", pp. 273-274.

${ }^{15}$ Cargo que velaba por la defensa de la ley en asuntos graves relacionados con el orden público y la seguridad del Estado. En ocasiones también era la figura competente para recaudar los impuestos. En el caso del zalmedina de Córdoba en época omeya, actuaba igualmente como regente. El cargo fue instituido por vez primera por 'Abd al-Raḥmān II; véase Ibn Sa īid, Al-Mugrib fì hulà-l-Magrib, I, p. 46. Consúltese acerca de esta figura Vallvé, "El zamedina de Córdoba" y Marín-Guzmán, Sociedad, política y protesta popular en la España Musulmana, pp. 63 y 135.

${ }^{16} \mathrm{Ibn}$ 'Abd al-Ra'ūf, Trois traités hispaniques, p. 86; Arié, “Traduction annotée”, p. 36.

${ }^{17}$ Ibn 'Abdūn, Trois traités hispaniques, p. 42; García Gómez, Sevilla a comienzos del s. XII, p. 133. 
precio o tarifa del producto en cuestión establecido el día en que tuvo lugar el acaparamiento ${ }^{18}$. También al-Saqaṭi lo prohíbe cuando resulta un perjuicio para las gentes y, por otra parte, en tiempos de escasez el grano ha de venderse en el zoco, no en las $\operatorname{casas}^{19}$.

Los autores de manuales de hisba, por otra parte, manifiestan la necesidad de que el almotacén participe, en mayor o menor medida, en la fijación de los precios. 'Umar al-Ŷarsīfí, en su breve tratado, vincula la actuación del almotacén a esta función en las dos referencias explícitas al precio de los productos que contiene su obra. Dice el autor que, con respecto al precio de los alimentos, el responsable de la hisba debe fijar un precio cuando esto sea lícito y en el momento permitido, además de vigilar la venta a un precio no explícito ${ }^{20}$. Por otra parte, siempre que se haya cambiado el precio de un objeto por estar adulterado o deteriorado, el almotacén lo hará saber colocando una señal distintiva ${ }^{21}$. Por su parte, al-Saqațī establece que el almotacén hará importar el trigo en previsión de una subida de precios ${ }^{22}$ y son los panaderos quienes le piden a aquél que fije el precio del pan $^{23}$.

No obstante, la cuestión de si es lícito o no fijar los precios del mercado $^{24}$ resulta ser el asunto más controvertido cuando contrastamos los tratados de hisba y, por otra parte, parece tratarse de una de las bases fundamentales en que se asienta el sistema comercial medieval islámico y la ordenación de su funcionamiento cotidiano. De hecho, está presente en todas las obras relativas a la administración del mercado, ya sea de forma explícita o no.

Históricamente, encontramos en la jurisdicción islámica una postura

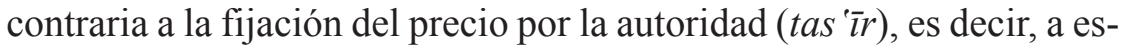

${ }^{18}$ Ibn 'Abd al-Ra'ūf, Trois traités hispaniques, p. 109; Arié, "Traduction annotée", pp. 358-359.

${ }^{19}$ Al-Saqațī, Un manuel hispanique de hisba, p. 5; Chalmeta, "El Kitāb fì ādāb alhisba", p. 369.

20 "Umar al-Ŷarsīfì, Trois traités hispaniques, pp. 120-121; Arié, "Traduction annotée", pp. 366-367. En el original maŷhül; Arié traduce el término como "non convenu".

21 'Umar al-Ŷarsīfī, Trois traités hispaniques, p. 125; Arié, "Traduction annotée", p. 371.

${ }^{22}$ Al-Saqațī, Un manuel hispanique de hisba, p. 11; Chalmeta, "El Kitāb fì ādāb alhisba", p. 380.

${ }^{23}$ Al-Saqațī, Un manuel hispanique de hisba, p. 27; Chalmeta, "El Kitāb fì ādāb alhisba", p. 155.

${ }^{24}$ Sobre esta discusión, cfr. Chalmeta, El zoco medieval, p. 430 y ss. Véase también García Sanjuán, "El control de los precios". 
tablecer una equivalencia entre la cantidad de producto que el vendedor da y su contrapartida monetaria. En este caso, se considera que el tas 'itr es ilícito (harām) y se aduce para ello algún pasaje coránico ${ }^{25}$ y algunos hadices en que el Profeta se habría negado a fijar equivalencias ${ }^{26}$.

Los textos de hisba recogen esta polémica y transmiten en ocasiones posturas contradictorias. Yahyà $b$. 'Umar, por ejemplo, en un largo párrafo al inicio de su obra sobre la fijación de precios a panaderos, verduleros y otros vendedores del zoco, nos dice que, según Mālik, se considera bueno fijar el precio ${ }^{27}$. Sin embargo, más adelante, y recabando igualmente el criterio de Mālik, se censura la fijación de precios $\mathrm{y}$, en concreto, establecer un precio más bajo del habitual para un trigo de peor calidad al tiempo que se obliga al resto de vendedores a bajar la tarifa ${ }^{28}$. Incluso cuando se trata del trigo, en caso de que suban los precios y sea menester que los acaparadores saquen a la venta aquél que tienen guardado, no se les ha de fijar un precio ${ }^{29}$. También al-Saqațī, en las consideraciones iniciales de su tratado, recoge el testimonio del Profeta según el cual se habría negado a fijar los precios por considerarlo una atribución divina ${ }^{30}$, si bien a lo largo de dicha obra se suceden las alusiones a los mismos y las fórmulas para establecerlos.

Otros juristas consideran que hay un precio del mercado, un precio conocido y aceptado por todos, y que se establecía de acuerdo a la "ley de la oferta y la demanda"31. En los tratados de hisba encontramos menciones de productos cuyo precio puede subir y bajar, como en el caso de los vendedores de telas que tienen mercancías adquiridas desde hace tiempo, citados por Ibn 'Abd al-Ra' $\overline{\mathrm{u}} \mathrm{f}^{32}$. Ibn 'Umar recoge un caso que

${ }^{25}$ Corán 4:29.

${ }^{26}$ Ibn Maŷŷa, Tî̀arāt, 27; Al-Tirmid̄ī, Buyū', 73.

${ }^{27}$ Yahyyà Ibn 'Umar, Kitāb aḥkām al-sūq, pp. 50-52; García Gómez, "Unas ordenanzas del zoco del s. IX", pp. 272-273.

${ }^{28}$ Yahyà Ibn 'Umar, Kitāb ahkām al-sūq, pp. 74-75; García Gómez, "Unas ordenanzas del zoco del s. IX", p. 296.

${ }^{29}$ Yaḥyà Ibn 'Umar, Kitāb ahkām al-sūq, p. 77; García Gómez, "Unas ordenanzas del zoco del s. IX", p. 299.

${ }^{30}$ Al-Saqațī, Un manuel hispanique de hisba, p. 5; Chalmeta, "El Kitāb fì ādāb alhisba", p. 368.

${ }^{31}$ Sigo en este punto a P. Chalmeta, que explica, justifica y matiza el uso de éste y otros términos propios de la ciencia económica. Véase El zoco medieval, p. 308 y pp. 355359. En el artículo de Talbi ya citado se emplea, por ejemplo, el término "libéralisme économique" para calificar la postura jurídica contraria a la tarificación.

${ }^{32} \mathrm{Ibn}$ 'Abd al-Ra'ūf, Trois traités hispaniques, p. 86; Arié, “Traduction annotée”, p. 35. 
ilustra cómo se entendía que la población debía estar al corriente de determinados precios y, de nuevo, la convivencia de dos sistemas tarifarios, según se trate del zoco de la ciudad o de zonas rurales: un forastero llega al mercado de la ciudad y no sabe el precio del aceite o trigo. Según Saḥnūn, estos precios han de conocerse por fuerza. Según el autor de la obra, sin embargo, este comprador ha de ser informado expresamente ${ }^{33}$.

Y podríamos hablar de una tercera postura, según la cual los precios del mercado son fijados en casos de necesidad, es decir, se admite la tarificación, como en el caso de la escuela mālikí -predominante en alAndalus-, en casos muy excepcionales, cuando había precios desorbitados para alimentos de primera necesidad y buscando, por tanto, el bien común ${ }^{34}$.

En la práctica, en la vida diaria del mercado, lo cierto es que los precios de los productos en general se establecían mediante un acuerdo entre las partes, el vendedor y el comprador, para fijar finalmente la cantidad que se entrega por un género. Procedimientos como el regateo, sin embargo, no se utilizaban en el caso de los alimentos considerados de primera necesidad, como el pan, porque en estos casos hay un consenso, todo el mundo en el mercado conoce o debería conocer su precio $^{35}$. La preocupación sobre el precio de los cereales, en particular, se trasluce en los manuales de hisba: Ibn 'Abd al-Ra'üf afirma que se prohíbe a los comerciantes del zoco que fijen el precio del trigo ${ }^{36}$, será ésta una labor encomendada al imán en pro del bien común; Ibn 'Abdūn, por su parte, recoge una interesantísima referencia a la necesidad de deducir los gastos de la siega antes de calcular la cosecha de cereales ${ }^{37}$, siendo Córdoba el ejemplo a seguir en este aspecto. En esta obra, que gira en torno al mercado de Sevilla, los cereales aparecen citados en otras dos ocasiones en relación a los precios por constituir un alimento

${ }^{33}$ Yahyyà Ibn 'Umar, Kitāb ahkām al-sūq, p. 79; García Gómez, "Unas ordenanzas del zoco del s. IX", p. 301.

${ }^{34}$ Véase Maŷîldī, Kitāb al-taysīr fì aḥkām al-tas 'īr, p. 52. Sobre esta limitación de la tarificación contemplada por los mālikíes, véase Talbi, "Fiqh et taxation", pp. 147-149.

${ }^{35}$ Véase Chalmeta, El zoco medieval, p. 400, n. 2. Sobre el precio del pan en al-Andalus, véase Ashtor, "Prix et salaires dans l'Espagne musulmane", p. 677.

${ }^{36} \mathrm{Ibn}$ 'Abd al-Ra'üf, Trois traités hispaniques, p. 88; Arié, "Traduction annotée”, p. 200.

${ }^{37}$ Ibn 'Abdūn, Trois traités hispaniques, p. 6; García Gómez, Sevilla a comienzos del s. XII, p. 45. 
básico: se prohíbe a los tratantes de trigo que suban los $\operatorname{precios}^{38}$ y se advierte sobre la necesidad de vigilar la venta de trigo a los acaparadores, operación que en muchos casos se hace sin control y provoca la subida de precios en el mercado ${ }^{39}$.

De hecho, donde sí encontramos una tarificación por parte de la autoridad es precisamente en los alimentos de primera necesidad, pues la jurisprudencia islámica entiende que debe velar por el bien común y garantizar el acceso de la masa de población a los artículos principales de consumo. En realidad, la fijación de precios solía darse casi exclusivamente sobre los alimentos, no sobre otros géneros del mercado ${ }^{40}$.

El almotacén actuará por tanto para evitar la inflación y también para fijar un límite en las ganancias de determinados gremios ${ }^{41}$. La operación puede hacerse de dos maneras. La primera es la denominada "precio impuesto", aplicada en casos de máxima gravedad, cuando está en peligro la paz social por la carestía de productos. En este caso, se impone un precio máximo, el más bajo posible, como medida de excepción y con una duración muy breve. El segundo procedimiento es lo que se da en llamar "precio acordado" y vendría ilustrado por el fragmento de al-Saqați relativo al establecimiento del precio de la carne que veremos más adelante.

Esta modalidad de tas 'ìr se denomina en árabe iqāmat o 'amal alqìma y consiste no en un acuerdo entre comprador y vendedor, sino entre la autoridad del zoco y un colectivo de vendedores ${ }^{42}$. Se trata de

${ }^{38}$ Ibn 'Abdūn, Trois traités hispaniques, p. 41; García Gómez, Sevilla a comienzos del s. XII, p. 129.

${ }^{39}$ Ibn 'Abdūn, Trois traités hispaniques, p. 42; García Gómez, Sevilla a comienzos del s. XII, p. 131.

${ }^{40}$ También cuando se trataba de alimentos solía establecerse la medida de destinar el producto requisado a limosnas tras detectar un fraude; véase García Sánchez, "Les traités de hisba andalous", p. 92.

${ }^{41}$ Utilizo a lo largo del trabajo este término, si bien, como es sabido, existe una discusión historiográfica acerca de si "gremio" -que incluso en lo que se refiere a la Europa medieval cristiana describiría organizaciones muy diversas- puede ser aplicado a las sociedades islámicas. Véase al respecto García Sanjuán, "La organización de los oficios en Al-Andalus". Es, de hecho, la voz utilizada por los traductores de las obras de hisba al español a la hora de referirse a los oficios. En todo caso, el especialista entenderá que con este vocablo nos referimos al hecho de que la pertenencia a un oficio constituía el germen de una corporación u organización, por simple que fuera, de tipo laboral.

${ }^{42} \mathrm{El}$ autor más antiguo que hizo referencia a esta modalidad de tarificación fue el andalusí Ibn Ḥabīb. Recoge su testimonio Ibn al-Bāŷī, Al-Muntaqā, V, p. 19. 
establecer una equivalencia consensuada que, una vez aceptada, es de carácter obligatorio. Los tratados de hisba andalusíes han transmitido el uso de este procedimiento aplicado a productos que se venden al por menor en las tiendas del zoco. Ibn 'Abd al-Ra'üf, por ejemplo, menciona la tarificación a partir de un precio acordado para el trigo, el aceite, la miel o la fruta ${ }^{43}$. Si se quiere fijar el precio de estos productos, se acordará un precio consensuado entre los comerciantes del zoco y el imán, después de que éste se haya informado de a qué precio han comprado el producto y a cómo lo venden. Se considera una tarifa lícita sólo si es aceptada de buen grado por todo el colectivo que comercia con el producto en cuestión y tiene como objeto evitar un precio excesivo en pro del interés público ${ }^{44}$.

\section{La venta de carne en los manuales de hisba}

Los autores que dedican más atención al gremio de los carniceros, en extensión y detalle, son Ibn 'Abd al-Ra'ūf y al-Saqaṭi. El capítulo dedicado a los carniceros y las alusiones dispersas en la obra de Ibn 'Abdūn a la carne son muy diversos, tanto en lo que se refiere a la calidad del producto como al comportamiento y normas de venta de los miembros de este gremio. Los autores se ocupan fundamentalmente del tema de los fraudes en la venta de la carne, el precio de la misma, la relación que los carniceros mantienen con el almotacén y diversas consideraciones sobre la calidad del producto y medidas higiénicas en el zoco.

\section{Los fraudes y su prevención}

Por la frecuencia con la que se citan en los manuales de hisba, los fraudes más usuales en el mercado relativos a la manipulación y venta de carne consistían, por una parte, en intervenir en la pesada, colocando huesos o restos similares en los platillos de las balanzas, como explica p. 200.

${ }^{43}$ Ibn 'Abd al-Ra'ūf, Trois traités hispaniques, pp. 88-89; Arié, "Traduction annotée",

${ }^{44}$ De este procedimiento para aplicar una tarifa se han conservado también referencias documentales en el caso de Egipto en el s. XVIII; véase Raymond, Artisans et commerçants au Caire au XVIII siècle, II, p. 565 y p. 604. 
Ibn 'Abdūn, de manera que la pesada sea mayor, por lo que las balanzas habrán de situarse siempre a la vista del comprador para evitar este fraude ${ }^{45}$ y en la obra se conmina a poner fin a esta práctica. También al-Saqați recoge esta trapacería cometida por los vendedores de carne ${ }^{46}$. Otro fraude que debió de practicarse en al-Andalus era la costumbre de soplar la carne para hincharla, recogido por $\mathrm{Ibn}^{\mathrm{C}} \mathrm{Umar}^{47}$ y por alSaqați ${ }^{48}$.

Ibn 'Abdūn, en un largo párrafo dedicado a los carniceros, donde se incluyen todo tipo de directrices sobre el sacrificio de reses y la venta de carne, sostiene que no puede venderse mezclada carne magra y grasa, que las tripas del cordero han de ser extraídas para que no se vendan al mismo precio de la carne, por constituir fraude, así como vender la carne con las vísceras, excepto en el caso de los $\operatorname{corderos}^{49}$. Ibn 'Umar igualmente recomienda no vender el pellejo de los carneros ${ }^{50}$.

Estos engaños debían de ser moneda corriente en los mercados andalusíes y del almotacén se esperaba su detección e intervención ante los posibles conflictos que pudieran surgir entre vendedores y compradores. 'Umar al-Ŷarsīî̀ recoge el caso de un hombre que reprobó a los carniceros del zoco por sus malas prácticas (bi-sū'i a 'māli-him), motivo por el que estos quisieron expulsarlo del mercado ${ }^{51}$.

\section{Relación con la autoridad}

Además del control de los fraudes, el almotacén intervenía en la actividad del gremio de los carniceros vigilando que los pesos y medidas

\footnotetext{
${ }^{45}$ Ibn 'Abdūn, Trois traités hispaniques, p. 55; García Gómez, Sevilla a comienzos del s. XII, p. 168.

${ }^{46}$ Al-Saqațī, Un manuel hispanique de hisba, p. 33; Chalmeta, "El Kitāb fì àdāb alhisba", 33/1 (1968), p. 168.

${ }^{47}$ Yahyyà Ibn 'Umar, Kitāb aḥkām al-sūq, p. 60; García Gómez, "Unas ordenanzas del zoco del s. IX", p. 281.

${ }^{48}$ Al-Saqațī, Un manuel hispanique de hisba, p. 32; Chalmeta, "El Kitāb fì ādāb alhisba", 33/1 (1968), pp. 166.

${ }^{49}$ Ibn 'Abdūn, Trois traités hispaniques, pp. 44-45; García Gómez, Sevilla a comienzos del s. XII, pp. 138-140.

${ }^{50}$ Yaḥyà Ibn 'Umar, Kitāb aḥkām al-sūq, p. 83; García Gómez, "Unas ordenanzas del zoco del s. IX", p. 305.

51 'Umar al-Ŷarsīfî, Trois traités hispaniques, p. 125; Arié, “Traduction annotée”, pp. 371-372.
} 
fueran los correctos y se ajustaran a los patrones establecidos. Ibn 'Umar aconseja a la autoridad del zoco que verifique que la balanza dé la medida justa de carne ${ }^{52}$. Ibn 'Abdūn, por su parte, afirma que las pesas de arrelde para la carne -también para el pescado- deben ser de hierro ${ }^{53}$.

Pero en el mercado andalusí había también otras figuras a las que el colectivo de vendedores de distintas clases de productos, a través del almotacén, reconocía como fuente de autoridad. Ibn 'Abd al-Ra'ūf, en su capítulo dedicado a la corporación de los carniceros, menciona la necesidad de que estos cuenten con un alamín (aminn) que les instruya sobre las reglas tradicionales del sacrificio de las reses ${ }^{54}$, ofreciendo una serie de consejos y directrices sobre la correcta realización de esta práctica según el rito islámico. Al-Saqațī establece la necesidad de que

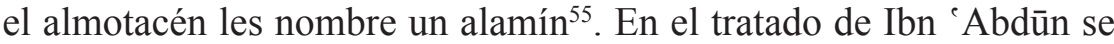
atribuye al alamín la función específica de identificar a los animales que puedan ser utilizados para el trabajo en el campo y que, por tanto, no habrán de ser sacrificados ${ }^{56}$.

Las autoridades jurídicas, obviamente, también actuarán sobre este colectivo cuando se considere que se ha vulnerado la ley: Ibn 'Abdūn alude a la costumbre de vender cosas robadas en el exterior de las puertas de Sevilla, entre ellas pieles y carne de ganado vacuno; el juez de la ciudad debe velar, a través de un alfaquí, por la legítima propiedad de estos productos y perseguir, en su caso, al que los haya robado ${ }^{57}$.

\section{Calidad e higiene}

Los manuales de hisba aluden a la preocupación por el estado de conservación de la carne, por tratarse de un producto de consumo dia-

${ }^{52}$ Yahyyà Ibn 'Umar, Kitāb ahkām al-sūq, p. 73; García Gómez, "Unas ordenanzas del zoco del s. IX", p. 295.

${ }^{53}$ Ibn 'Abdūn, Trois traités hispaniques, p. 40; García Gómez, Sevilla a comienzos del s. XII, p. 128.

${ }^{54} \mathrm{Ibn}$ 'Abd al-Ra'ūf, Trois traités hispaniques, pp. 93-94; Arié, “Traduction annotée", pp. 205-206.

${ }^{55}$ Al-Saqațī, Un manuel hispanique de hisba, p. 33; Chalmeta, "El Kitāb fì ādāb alhisba", 33/1 (1968), p. 169.

${ }^{56}$ Ibn 'Abdūn, Trois traités hispaniques, p. 44; García Gómez, Sevilla a comienzos del s. XII, pp. 138-139.

${ }^{57}$ Ibn ‘Abdūn, Trois traités hispaniques, p. 33; García Gómez, Sevilla a comienzos del s. XII, p. 111. 
rio, tanto en lo que se refiere al sacrificio de los animales como a la calidad que finalmente tiene la mercancía puesta a la venta.

Ibn 'Umar menciona la necesidad de que los matarifes efectúen correctamente el sacrificio de las piezas para que la nuez de la oveja no quede dentro del cuerpo ${ }^{58}$. Ibn 'Abdūn incluye todo tipo de directrices sobre el sacrificio de reses y la venta de carne e insiste en que la sangre de los animales sacrificados ha de sacarse del zoco ${ }^{59}$. Por su parte, 'Umar al-Ŷarsīfì insta a que no se eche a perder ni la carne ni las pieles de los animales que se sacrifican ${ }^{60}$. Por último, al-Saqațī menciona los casos de animales que por enfermedad, defectos físicos o, tratándose de hembras, estén preñadas, no pueden ser utilizados para el sacrificio ${ }^{61}$.

Entre las funciones del almotacén, también estaba la de velar por la calidad de la carne, y los manuales ofrecen indicaciones generales y también muy precisas a este respecto. Ibn 'Abd al-Ra'ūf recoge la orden que se ha de dar a los carniceros para que no vendan la carne del cuerpo del animal junto a la de otra parte de la pieza sacrificada ${ }^{62}$. Ibn 'Abdūn establece la prohibición de la venta de cecina de carne, por la escasa calidad de la materia prima, y se recomienda la elaboración de salchichas y brochetas con carne fresca ${ }^{63}$.

Algunos textos dan normas precisas para la venta, como cortar la carne en el lado izquierdo del carnicero para que el comprador vea el corte o la obligación de vender la carne de animales distintos en tiendas diferentes, según recoge al-Saqați ${ }^{64}$.

Por último, la higiene es otro aspecto por el que hay que velar para garantizar la buena marcha del zoco. Ibn 'Abdūn nos dice que ha de

\footnotetext{
${ }^{58}$ Yahyà Ibn 'Umar, Kitāb aḥkām al-sūq, pp. 82-83; García Gómez, "Unas ordenanzas del zoco del s. IX", pp. 304-305.

${ }^{59} \mathrm{Ibn}$ 'Abdūn, Trois traités hispaniques, pp. 44-45; García Gómez, Sevilla a comienzos del s. XII, pp. 138-139. 367.

60 'Umar al-Ŷarsīfì, Trois traités hispaniques, p. 121; Arié, "Traduction annotée”, p.

${ }^{61}$ Al-Saqațī, Un manuel hispanique de hisba, p. 32; Chalmeta, "El Kitāb fì ādāb alhisba", 33/1 (1968), pp. 166-167. 205.

${ }^{62} \mathrm{Ibn}$ 'Abd al-Ra'ūf, Trois traités hispaniques, p. 93; Arié, "Traduction annotée”, p.

${ }^{63} \mathrm{Ibn}$ `Abdūn, Trois traités hispaniques, p. 45; García Gómez, Sevilla a comienzos del s. XII, pp. 139-140.

${ }^{64}$ Al-Saqațī, Un manuel hispanique de hisba, pp. 33-34; Chalmeta, "El Kitāb fì ādāb al-hisba", 33/1 (1968), pp. 169-170.
} 
evitarse que la carne que se venda en el zoco manche a los transeúntes $\mathrm{y}$, particularmente, que se vierta la sangre de las cabezas de los corderos $^{65}$. Al-Saqați también establece normas higiénicas, como limpiar todos los días las esteras en que se coloca la carne o cubrir el tajo cada noche con esparto ${ }^{66}$.

\section{El precio de la carne}

Con respecto a este asunto, debemos diferenciar aquellos tratados que aluden al precio de la carne de una manera genérica, considerando ciertas normas que el vendedor debe respetar, de los autores que, como Ibn 'Umar, ofrecen precios concretos del producto, para terminar con el texto que presenta una mayor complejidad desde el punto de vista de la economía del mercado, el de al-Saqațī.

Dejando a un lado la obra de al-Ŷarsīîi, donde no encontramos ninguna referencia sobre el precio de la carne, debemos citar en primer lugar a Ibn 'Abdūn, autor que simplemente alude a la imposibilidad de vender un cordero de seis arreldes con sus tripas al mismo precio que la carne ${ }^{67}$.

Ibn 'Abd al-Ra' ûf, por su parte, incluye en su obra indicaciones de carácter general, como distintas prohibiciones sobre la venta de carne de la víspera y carne fresca mezcladas o la de carne magra y grasa mezcladas $^{68}$.

Siguiendo el criterio de Mālik, si se compra esta carne mezclada en pequeñas cantidades, por un precio de uno o dos dírhams, se considera lícito. Pero no así la compra de cantidades mayores, como veinte o treinta arreldes, a menos que pueda distinguirse el peso de una y otra.

${ }^{65}$ Ibn 'Abdūn, Trois traités hispaniques, p. 47 y 57; García Gómez, Sevilla a comienzos del s. XII, p. 147 y 173.

${ }^{66}$ Al-Saqațī, Un manuel hispanique de hisba, p. 33; Chalmeta, "El Kitāb fì àdāb alhisba", pp. 169-170.

${ }^{67} \mathrm{Ibn}$ 'Abdūn, Trois traités hispaniques, p. 44; García Gómez, Sevilla a comienzos del s. XII, p. 139. La traducción dice "No se venderá un cordero de seis arrates con sus tripas al mismo precio de otro que sólo de carne pese lo mismo".

${ }^{68} \mathrm{Ibn}$ `Abd al-Ra'ūf, Trois traités hispaniques, pp. 92-93; Arié, “Traduction annotée”, p. 204. 
Encontramos además en este tratado dos alusiones explícitas al precio de la carne. La primera refiere el hecho de que los carniceros se unan para sacrificar una sola pieza, operación que debe prohibirse si hace que aumente el precio pagado por el consumidor final. El pasaje en cuestión dice así:

Ha de impedírseles que se unan para sacrificar un mismo animal cuando eso repercute en el precio, pues la gente sólo puede pagar individualmente ${ }^{69}$.

Hacia el final de la obra, se incluye una nueva referencia a los carniceros, a los que, según el autor, debe prohibírseles comprar animales para el sacrificio durante los días de fiesta de la ${ }^{\top} \bar{A}$ šūrā ${ }^{\circ} 70$ y, en un aparente razonamiento contradictorio, se afirma que esto provoca la subida de precios, pero al mismo tiempo que no deben bajarse. El autor aclara que, en realidad, son las gentes las que deben establecer el precio de la venta. La traducción es la siguiente:

También se impedirá a los carniceros que compren las reses en los cercados a los tratantes por la 'Āšūrā' y luego las vendan pasada la feria, lucrándose y perjudicando así a la gente, pues aumentan los precios con gran beneficio para los carniceros. Es conveniente dejar que las gentes discutan, no bajar el precio ${ }^{71}$.

Es posible que este caso andalusí sea similar al fenómeno ya detectado en el Magreb según el cual en las ferias se vende al precio más bajo del año ${ }^{72}$. Esto explicaría que Ibn 'Abd al-Ra'ūf recoja aquí el proceder de los carniceros, que probablemente compraban los animales a bajo precio y obtenían un beneficio considerado excesivo para la hisba al vender la carne de los mismos una vez que han pasado los días de fiesta. El precio al que se compraba durante la feria ${ }^{73}$ constituía así una referencia para las transacciones posteriores.

No se recogen, sin embargo, en la obra de Ibn 'Abd al-Ra'ūf ejemplos de la relación producto/precio que puede o debe aplicarse en el caso de la carne. p. 206.

${ }^{69}$ Ibn 'Abd al-Ra'ūf, Trois traités hispaniques, p. 94; Arié, "Traduction annotée", 727. 360 .

${ }^{70}$ Sobre esta fiesta musulmana y su relación con ritos agrarios, véase $E I^{2}, \mathrm{I}, \mathrm{pp} .726$ -

${ }^{71}$ Ibn 'Abd al-Ra'ūf, Trois traités hispaniques, p. 110; Arié, "Traduction annotée”, p.

${ }^{72}$ Véase Simenel, "Le Grand Commerce de la baraka", pp. 218-220.

${ }^{73}$ Sobre el concepto de feria/mawsim, véase Chalmeta, El zoco medieval, pp. 377-387. 
El texto de Ibn 'Umar es mucho más preciso. Según sus recomendaciones, la carne de carnero y de cabra no debería venderse mezclada, pues les correspondería un precio distinto a cada una ${ }^{74}$, pero sí sería posible vender conjuntamente carne magra y grasa - no se especifica el animal- siempre que se trate de poca cantidad ${ }^{75}$. Es éste uno de los pocos casos en que se ofrece al lector un precio, entendido como "equivalencia" o "relación" entre la cantidad de producto que se entrega y el dinero que se da en pago ${ }^{76}$. Se afirma que, en caso de tratarse de cinco o seis arreldes de carne mezclada magra y grasa, la gente lo compra a uno o dos dírhams. Si se da el caso de que un carnicero mezcle carnero con cabra o carne magra y grasa y al ser sorprendido huya, el almotacén debe cerrarle la tienda ${ }^{77}$.

Al final del tratado el autor, aprobando la opinión del alfaquí Ibn Țālib, nos ofrece una información muy precisa sobre cómo ha de venderse la carne y de nuevo aporta una relación producto/precio: existe prohibición de vender tanto el corazón como las tripas del animal conjuntamente con la carne, puesto que la relación entre cantidad de producto y dinero ha de ser necesariamente distinta. Así, se pagaría un dírham por dos arreldes de carne y un dírham por seis arreldes de tripas ${ }^{78}$.

Equivalencia de tarifa o precio final según Ibn 'Umar:

\begin{tabular}{|c|c|}
\hline $\begin{array}{c}5 \text { ó } 6 \text { arreldes de carne magra } \\
\text { y grasa mezclada }\end{array}$ & 1 ó 2 dírhams \\
\hline 2 arreldes de carne & 1 dírham \\
\hline 6 arreldes de tripas & 1 dírham \\
\hline
\end{tabular}

${ }^{74}$ Yahyà Ibn 'Umar, Kitāb aḥkām al-sūq, p. 60; García Gómez, "Unas ordenanzas del zoco del s. IX", p. 281.

${ }^{75}$ Yaḥyà Ibn 'Umar, Kitāb aḥkām al-sūq, p. 59; García Gómez, "Unas ordenanzas del zoco del s. IX", p. 280.

${ }^{76}$ Véase, sobre este concepto, Chalmeta, El zoco medieval, pp. 408-409.

${ }^{77}$ Yahyyà Ibn 'Umar, Kitāb a ḥkām al-sūq, p. 62; García Gómez, "Unas ordenanzas del zoco del s. IX", p. 283.

${ }^{78}$ Yahyyà Ibn 'Umar, Kitāb aḥkām al-sūq, p. 85; García Gómez, "Unas ordenanzas del zoco del s. IX", p. 308. 
El tratado de al-Saqați va un paso más allá y ofrece la fórmula exacta para calcular el precio de la carne. Los autores del artículo publicado en Revista de contabilidad, citado al inicio de este trabajo, describen con detalle la fórmula, pero el texto árabe merece algunas precisiones y comentarios no recogidos allí.

El pasaje en cuestión se localiza al final del capítulo dedicado a los carniceros, en el que también se habla del pescado, las salchichas, la harīsa, dulces como los buñuelos o los roscos y el asado de carne. El peso se calcula en arreldes, medida de peso que varía según las zonas geográficas. Por ejemplo, en Marruecos equivale a 508 gramos. P. Chalmeta nos dice que en al-Andalus, con todas las reservas que puedan hacerse -porque los pesos y medidas, en contra de lo que pudiera pensarse, variaban su valor dependiendo del lugar y la época de que se hable, incluso variaban en un mismo sitio y en un mismo período-, el arrelde de carne equivaldría a 2.020 grs. $^{79}$. Para establecer este cálculo se parte del peso del dírham y de considerar que el arrelde es igual a 64 auquías u onzas ${ }^{80}$.

Es el siguiente:

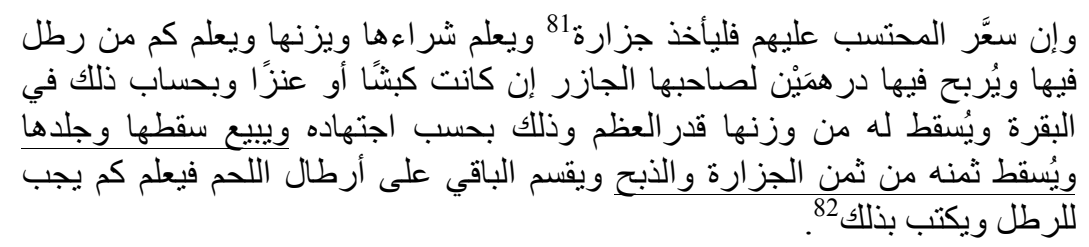

${ }^{79}$ Véase la introducción a la traducción de este tratado, "El Kitāb fì ādāb al-hisba", pp. 156-157. Sobre el arrelde en período cristiano (1.840 grs. aproximadamente, aunque, como en el espacio islámico, están acreditadas equivalencias distintas, dependiendo de la zona), véase la interesantísima y reciente obra de Castaño, El libro de los pesos y medidas, pp. 257-260. Recomendable es la lectura de su introducción, donde se explica la frustrante $\mathrm{y}$, en ocasiones, inútil tarea de querer buscar la correspondencia de las unidades antiguas de medida con las del Sistema Métrico Decimal.

${ }^{80}$ Equivalencia dada por el propio al-Saqațī, Un manuel hispanique de hisba, p. 37.

${ }^{81}$ El término ŷuzāra denomina en árabe clásico a la res, a la pieza de ganado que se sacrifica. También a los despojos de la misma y al salario que recibe un matarife. Véanse los diccionarios de Kazimirski y Lane, s.v.

${ }^{82}$ Al-Saqațī, Un manuel hispanique de hisba, p. 34. 


\section{La traducción de P. Chalmeta de 1968 dice:}

Caso de que el almotacén les fijase los precios, lo hará tomando una res, informándose de a cuanto se compró y pesándola para saber cuantos arreldes tiene. Señalará dos dirhemes de ganancia al carnicero si fuere carnero o cabrón, y en proporción caso de que sea vaca. Restará del peso de la res el de los huesos que calculará aproximadamente, más el [coste del] degüello, sumando luego el producto de la venta de los despojos y pellejo. Al dividir el resultado por el número de arreldes de carne sabrá a cuanto equivale cada arrelde, inscribiendo dicho cociente donde el comprador lo vea ${ }^{83}$.

En 2014 apareció una nueva edición revisada del texto árabe del tratado de al-Saqațī, acompañada de su traducción, a cargo de los doctores P. Chalmeta y F. Corriente. A pesar de que no se indica la modificación realizada, el fragmento relativo al precio de la carne ha sido revisado de este modo:

"[...] Restará del peso de la res el de los huesos, que calculará aproximadamente. Se venderá la piel y despojos, cuyo importe descontará del coste de la res y degüello; dividiendo el resultado por el [número de arreldes de] carne sabrá a cuánto equivale cada arrelde, inscribiendo dicho cociente como albarán para el vendedor" 84 .

La segunda traducción resuelve una posible ambigüedad. Al traducir la oración verbal subrayada en el texto árabe con el gerundio "[...] sumando luego el producto de la venta de los despojos y pellejo", la traducción de P. Chalmeta de 1968 podría generar dudas acerca de si el coste de los desechos y la piel se añade al peso de la res para calcular cuánto vale una pieza o bien, como parece ser lo más acertado al revisar el texto, se restan; esto es, para calcular el precio del arrelde o libra de carne, se sustrae el precio tanto de los huesos, como de todos los desechos y la piel. De manera que para fijar el precio de la carne se utiliza como referencia el peso de la pieza y luego se resta el valor de los hue$\operatorname{sos}^{85}$, los desperdicios o desechos, la piel y el coste del degüello. La precisión de la fórmula ofrecida por el autor malagueño para la fijación

83 "El Kitāb fì ādāb al-hishb", p. 171.

${ }^{84}$ Al-Saqați al-Mālaqī, El buen gobierno del zoco, p. 112.

${ }^{85}$ En otro momento de la obra de al-Saqațī se recuerda que para establecer el precio de la carne se ha tenido ya en cuenta el peso de los huesos, precisamente al citar uno de los engaños de los carniceros: vender carne con gran cantidad de hueso; Al-Saqațī, Un manuel hispanique de hisba, p. 33; Chalmeta, "El Kitāa fi ādāb al-ḥisba", p. 169. 
del precio de la carne hace que la revisión de este fragmento sea muy pertinente.

La meticulosidad y el carácter práctico de este tratado van mucho más allá, porque en sus páginas también podemos encontrar el procedimiento utilizado para calcular el precio del pan, teniendo en cuenta el coste de la mano de obra y la inversión por la leña utilizada ${ }^{86}$, así como la fórmula para calcular el coste de las almojábanas, que incluye, por ejemplo, el sueldo del amasador, el alquiler de la tienda o el precio de la leña, el coste de la harīsa, de los buñuelos, de las longanizas y de las albóndigas ${ }^{87}$.

El texto de al-Saqațī, como hemos visto, recoge el cálculo del coste de la venta, entre otros, de carne, operación que siempre se llevará a cabo cuando se establece el «precio acordado» y, además, va acompañada de la fijación de un beneficio para el vendedor, de manera que se le garantice una ganancia. Al mismo tiempo, se establece un precio considerado justo para el comprador. Este fragmento es indicativo del grado de complejidad que pudo llegar a tener el sistema tarifario medieval, que incorporaba el cálculo de costes en la normativa sobre el zoco: al calcular el precio de un género como la carne, al calcular la qìma correspondiente, se tiene en cuenta la inversión que supone el gasto del sacrificio de la pieza (el degüello).

Durante mucho tiempo, los historiadores especialistas en contabilidad han venido considerando que el cálculo de costes comienza en el s. XIX en América con la revolución industrial y el aumento de la competencia ${ }^{88}$. Sin embargo, ya se han publicado reveladores trabajos que demuestran que en los siglos XVI-XVII el cálculo de costes fue utilizado como instrumento para la fijación de los precios ${ }^{89}$. Y es evidente, como hemos visto, que es éste un concepto ya presente en la normativa medieval islámica sobre el zoco. A este respecto hemos de añadir que en los planteamientos económicos de la Muqaddima de Ibn Jaldūn (1332-1406) encontramos el análisis teórico de esta herramienta de

\footnotetext{
${ }^{86}$ Al-Saqațī, Un manuel hispanique de hisba, pp. 27-28; Chalmeta, "El Kitāb fì ādāb al-hisba", pp. 156-157.

${ }^{87}$ Al-Saqați, Un manuel hispanique de hisba, pp. 31-32; Chalmeta, "El Kitāb fì ādāb al-hisba", pp. 164-165.

${ }^{88}$ Véase, por ejemplo, la introducción del artículo de Gutiérrez, Larrinaga y Núñez, "Cost and management accounting", pp. 111-113.

${ }^{89}$ Carmona y Donoso, "Precios, espíritu de beneficios y sistemas de costes", donde se analiza el caso de las Reales Almonas de Sevilla.
} 
contabilidad, pues el gran historiador de origen andalusí analiza aquí cómo los costes de producción influyen en la oferta de los productos y en el precio de las cosas. En el capítulo IV de su obra ${ }^{90}$, entre otros ejemplos, menciona el caso de tierras poco propicias para la producción agrícola, donde la población debe introducir una serie de mejoras que suponen un coste adicional y éste finalmente tiene su reflejo en el precio de venta de los productos. Considera el autor que esto es lo que ocurre en su tiempo en al-Andalus tras el avance cristiano, donde se dan precios altos, mientras que en territorio bereber (bilād al-barbar) la tierra es tan fértil que no es necesario añadir ningún gasto, lo que propicia precios más bajos.

\section{Otras noticias}

Las obras consideradas de hisba, finalmente, por su variedad y tipología (recopilación de consultas jurídicas, manual dirigido al futuro almotacén, etc.), nos han legado también otros datos sobre diversos aspectos de la vida diaria en el mercado y, en particular, relativos a la actividad de los carniceros.

Ibn 'Umar, por ejemplo, nos habla de la posibilidad de que un miembro de esta comunidad pueda vender en solitario en el mercado durante uno o dos días ante una necesidad imperiosa (por ejemplo, va a casarse $)^{91}$. El texto da a entender que se trataba de un uso practicado a voluntad del propio gremio, con independencia de la autoridad del zoco, lo que denota cierto grado de autonomía en esta corporación, si bien el almotacén debía vigilar los precios aplicados en la venta.

Ibn 'Abdūn recoge la única alusión a uno de los impuestos pagados por los carniceros, el de alcabala, que, según el texto de la Risāla, ha de estar fijado con antelación para que no suba en el caso de un animal que se compra para ser sacrificado ${ }^{92}$. En su obra encontramos también

${ }^{90}$ Ibn Jaldūn, Al-Muqaddima, vol. 2, p. 213; Introducción a la historia universal (alMuqqadima), pp. 659-660. Consúltese también Maskanul Hakim, "Ibn Khaldun's thought in microeconomics: dynamic of labor, demand-supply and prices".

${ }^{91}$ Yaḥyà Ibn 'Umar, Kitāb aḥkām al-sūq, p. 60; García Gómez, "Unas ordenanzas del zoco del s. IX", p. 281.

${ }^{92}$ Ibn 'Abdūn, Trois traités hispaniques, p. 31; García Gómez, Sevilla a comienzos del s. XII, p. 107. 
un comentario sobre la comunidad judía, en el sentido de que se prohíbe que los miembros de la misma sacrifiquen reses para el consumo de los musulmanes, pues han de tener carnicerías propias ${ }^{93}$. Por otra parte, el autor sevillano exige que los vendedores de carne y pescado no se enriquezcan, dada la naturaleza de estos productos ${ }^{94}$.

Ibn 'Abd al-Ra'üf, por su parte, menciona los casos en que un animal es lícito para el sacrificio ${ }^{95}$ y al-Saqațī, por último, en su manual caracterizado por su precisión y voluntad de transmitir los usos del mercado en tiempos del propio autor, nos da distintas recetas y elaboraciones descritas al detalle, como la preparación de las salchichas y albóndigas ${ }^{96}$, la del guiso de carnero con sus tripas y carne de caza ${ }^{97}$, la receta del asado de carne ${ }^{98} \mathrm{o}$ la fórmula por la que se elabora fraudulentamente la haris $a^{99}$.

\section{Conclusión}

Fuentes como el Kitāa fì ādāb al-hisba, junto con los demás tratados de hisba andalusíes, siguen siendo muy valiosas para definir con mayor precisión las condiciones económicas e ideológicas en que se desarrollaban las transacciones comerciales, así como la importancia del comercio para la sociedad islámica medieval ${ }^{100}$. En cuanto a los precios en particular, observamos en las obras de este género, en primer lugar, una preocupación sobre su vigilancia y regulación, si bien no

${ }^{93}$ Ibn 'Abdūn, Trois traités hispaniques, p. 49; García Gómez, Sevilla a comienzos del s. XII, p. 152.

${ }^{94}$ Ibn `Abdūn, Trois traités hispaniques, p. 53; García Gómez, Sevilla a comienzos del s. XII, p. 162. 208.

${ }^{95}$ Ibn 'Abd al-Ra'ūf, Trois traités hispaniques, p. 96; Arié, "Traduction annotée”, p.

${ }^{96}$ Al-Saqațī, Un manuel hispanique de hisba, p. 36; Chalmeta, "El Kitāb fì ādāb alhisba", pp. 174-175.

${ }^{97} \mathrm{Al}-\mathrm{Saqați}$, Un manuel hispanique de hisba, p. 39; Chalmeta, "El Kitāb fì ādāb alhisba", p. 179-181.

${ }^{98}$ Al-Saqațī, Un manuel hispanique de hisba, p. 40; Chalmeta, "El Kitāb fì ādāb alhisba", p. 182.

${ }_{99}$ Al-Saqațī, Un manuel hispanique de hisba, p. 37; Chalmeta, "El Kitāb fì ādāb alhisba", p. 176.

${ }^{100}$ Asimismo, otro campo en que aún están pendientes trabajos relativos a los mercados es el arqueológico; véase Curta, "Markets in Tenth-Century al-Andalus and Volga Bulghāria”. 
puede afirmarse que el almotacén ejerciera un estricto control sobre los mismos. Sí tenía entre sus atribuciones de forma inequívoca la supervisión de los precios, pero la intervención sobre los mismos, a tenor de los textos conservados, únicamente se produciría en el caso de los alimentos de primera necesidad o considerados básicos, y, por otro lado, cuando fuera necesaria alguna medida excepcional (carestía, revueltas sociales, etc.).

La institución de la hisba, por tanto, y a pesar de que los distintos tratados no muestran una postura unánime al respecto, tendería a intervenir sobre los precios, garantizando el bien común y buscando mantener una cierta estabilidad en las tarifas, que, hemos de suponer, debía de regir en las transacciones cotidianas del mercado. Así hemos de interpretar las alusiones a precios considerados "de referencia", como los utilizados en las ferias, o el hecho de que los compradores debían estar al corriente de tarifas usuales en el zoco.

La normativa de hisba, en definitiva, vela por los intereses de vendedores y compradores, pretende garantizar la calidad y el abastecimiento de los productos de consumo cotidiano y atribuye a la máxima autoridad del zoco la tarea de asegurar la buena marcha del mismo, evitar la inflación y responder, al menos en el plano teórico, al cumplimiento de la ley islámica.

\section{Bibliografía}

Arié, Rachel, "Traduction annotée et comentée des traités de hisba de Ibn 'Abd al-Ra'ūf et de 'Umar al-Garsīf̂”', Hespéris-Tamuda, 1/1 (1960), pp. 5-38, 1/2, pp. 199-214, 1/3, pp. 349-386.

Ashtor, Eliyahu, "Prix et salaires dans l'Espagne musulmane", Annales. Économies, Sociétés, Civilisations, 4 (1965), pp. 664-679.

al-Bāŷî, Abū l-Walīe, Al-Muntaqā, El Cairo, $1332 \mathrm{H}$.

Carmona, Salvador y Donoso, Rafael, "Precios, espíritu de beneficios y sistemas de costes", Revista Española de Financiación y Contabilidad, 100 (1999), pp. 403-424.

Castaño, José, El libro de los pesos y medidas, Madrid, La esfera de los libros, 2015.

Chalmeta, Pedro, "El Kitāb fì ādāb al-hisba (Libro del buen gobierno del zoco) de Al-Saqați”, Al-Andalus, 32/1 (1967), pp. 125-162, 32/2 (1967), pp. 359397, 33/1 (1968), pp. 143-195, y 33/2 (1968), pp. 367-434. 
Chalmeta, Pedro, El 'señor del zoco'en España: edades media y moderna, Madrid, Instituto Hispano-Árabe de Cultura, 1973.

Chalmeta, Pedro, El zoco medieval. Contribución al estudio de la historia del mercado, Almería, Fundación Ibn Tufayl de Estudios Árabes, Cajamar, 2010.

Chalmeta, Pedro, "Al-Saqațī, Abū 'Abd Allāh" en Biblioteca de al-Andalus: De al-Qabrirī a Zumurrud, Almería, Fundación Ibn Tufayl de Estudios Árabes, 2012, vol. VII, pp. 286-292 [n 1697].

Curta, Florin, "Markets in Tenth-Century al-Andalus and Volga Bulghāria: Contrasting Views of Trade in Muslim Europe", Al-Masaq, 25/3 (2013), pp. 305330.

Encyclopédie de l'Islam, Leiden, París, Brill, Maisonneuve et Larose, 1977-2007 $\left[E I^{2}\right]$.

García Gómez, Emilio, Sevilla a comienzos del s. XII. El tratado de Ibn 'Abdūn, Madrid, 1948.

García Gómez, Emilio, "Unas ordenanzas del zoco del s. IX: traducción del más antiguo antecedente de los tratados andaluces de hisba", Al-Andalus, 22 (1957), pp. 253-316.

García Sánchez, Expiración, "Les traités de hisba andalous: un exemple de matière médicale et botanique populaires", Arabica, 44/1 (1997), pp. 76-93.

García Sanjuán, Alejandro, "La organización de los oficios en al-Andalus a través de los manuales de Hisba", Historia. Instituciones. Documentos, 24 (1997), pp. 201-233.

García Sanjuán, Alejandro, "El control de los precios en la jurisprudencia islámica andalusí", Philologia Hispalensis, 14/2 (2000), pp. 217-231.

Gimaret, Daniel, "Les theologiens musulmans devant la hausse des prix", Journal of the Economic and Social History of the Orient, 22/3 (1979), pp. 330-338.

Gutiérrez, Fernando, Larrinaga, Carlos y Núñez, Miriam, “Cost and management accounting in pre-industrial revolution Spain", Accounting Historians Journal, 32/1 junio (2005), pp. 111-148.

Ibn 'Abd al-Ra'ūf, Risāla fì ādāb al-hiisba wa-l-muhtasib en Trois traités hispaniques de hisba, Évariste Lévi-Provençal (ed.), El Cairo, 1955, pp. 67-116.

Ibn 'Abdūn, Risāla fì l-qāọ̄à' wa-l-hisba en Trois traités hispaniques de hisba, Évariste Lévi-Provençal (ed.), El Cairo, 1955, pp. 3-65.

Ibn Jaldūn, Al-Muqaddima, 'Abd al-Salām al-Šaddaādī (ed.), al-Dār al-Bayḍā', Bayt al-Funūn wa-1- 'Ulūm wa-1-Ādāb, 2005, 3 vols.

Ibn Jaldūn, Introducción a la historia universal (al-Muqaddima), Francisco Ruiz Girela (trad.), Córdoba, Almuzara, 2008.

Ibn Sa īid, Al-Mugrib fì hulà-l-Magrib, ed. Šawqī Ḍayf, El Cairo, 1953.

Kazimirski, Albert de Biberstein, Dictionnaire Arabe-Français, París, 1860 (reprod. Beirut, Librairie du Liban, 1975).

Lane, Edward William, An Arabic-English lexicon: derived from the best and the most copious Eastern sources, London, Williams and Norgate, 1863-1893. 
Lévi-Provençal, Évariste, "Un document sur la vie urbaine et les corps de métiers à Séville au debut du XII ${ }^{\mathrm{e}}$ siècle: le traité d'Ibn 'Abdūn”, Journal Asiatique, 224 (1934), pp. 177-299.

López Manjón, Jesús Damián, Gutiérrez Hidalgo, Fernando y Carrasco Fenech, Francisco, "El olvido de un sistema de cálculo de costes andalusí (primer tercio del siglo XIII)", Revista de Contabilidad-Spanish Accounting Review (2015) [en línea], doi: 10.1016/j.rcsar.2014.11.001.

Makkī, Maḥmūd 'Alī, "Nașs ŷadīd fī l-ḥisba: Kitāb aḥkām al-sūq li-Yahyà b. 'Umar al-Andalusī”, RIEI, 4 (1956), pp. 59-151.

Marín-Guzmán, Roberto, Sociedad, política y protesta popular en la España Musulmana, San José, Universidad de Costa Rica, 2006.

Maskanul Hakim, Cecep, "Ibn Khaldun's thought in microeconomics: dynamic of labor, demand-supply and prices", ponencia presentada al Encuentro Internacional sobre tradición y modernidad en el pensamiento económico árabe-musulmán: "La contribución de Ibn Jaldún”, Madrid (3-5 noviembre, 2006), [en línea] http://www2.uned.es/congreso-ibn-khaldun/pdf/03\%20 Cecep\%20Hakim.pdf.

al-Maŷīldī, Kitāb al-taysīr fì ahkām al-tas '̄ir , ed. M. Laqbal, Argel, 1971.

Müller, Christian, Gerichtspraxis im Stadtstaat Córdoba: zum Recht der Gesellschaft in einer malikitisch-islamischen Rechtstradition des 5./11. Jahrhunderts, Leiden, E. J. Brill, 1999.

Napier, Christopher, "Defining Islamic accounting: current issues, past roots", Accounting History, 14/1-2 (2009), pp. 121-144.

Raymond, André, Artisans et commerçants au Caire au XVIII siècle, Damasco, 1973. al-Saqațī, Abū 'Abd Allāh, Kitāa fì ādāb al-hisba en Un manuel hispanique de hisba: traité d'Abū 'Abd Allāh Muhammad b. Abī Muhammad as-Sakațī de Málaga, traité sur la surveillance des corporations et la répression des fraudes en Espagne Musulmane, G. S. Colin y Évariste Lévi-Provençal (ed.), Paris, Publications de l'Institut des Hautes-Etudes Marocaines, 1931, t. XXI. al-Saqațī al-Mālaqī, El buen gobierno del zoco, Pedro Chalmeta y Federico Corriente (ed.) y Pedro Chalmeta (estudio y trad.), Almería, Fundación Ibn Tufayl de Estudios Árabes, 2014.

Simenel, Romain, "Le Grand Commerce de la baraka: les moussem du Sud Marocain", en F. Mermier y M. Peraldi (ed.), Mondes et places du marché en méditerranée: formes sociales et spatiales de l'échange, París, Karthala, 2011, pp. 215-225.

Talbi, Mohamed, "Fiqh et taxation (tas 'īr)", Cahiers de Tunisie, 25/139-142 (1987), pp. 121-158.

Trois traités hispaniques de hisba, ed. Évariste Lévi-Provençal, El Cairo, L’Institut français d'archéologie orientale, 1955.

'Umar al-Ŷarsīfī, Risāla fì l-hisba en Trois traités hispaniques de hisba, ed. Évariste Lévi-Provençal, El Cairo, 1955, pp. 117-128. 
Vallvé, Joaquín, "El zalmedina de Córdoba", Al-Qanțara, 1 (1981), pp. 277-318. Wickens, George Michael, "Al-Jarsīfì on the hisba", Islamic Qarterly, $3 / 4$ (1956), pp. 176-187.

Yaḥyà Ibn 'Umar al-Andalusī, Kitāb aḥkām al-sūq, ed. Maḥmūd 'Alī Makkī, AlQahira, Maktabat al-țaqāfa al-dīniyya, 2004/1424.

Recibido: 19/03/2016

Aceptado: 10/09/2018 